\title{
Lori's Help: um aplicativo para auxílio na alfabetização de pessoas com Síndrome de Down
}

\author{
Marcus Vinicius Girolneto Sousa ${ }^{1}$, \\ Dione Ramos ${ }^{1}$ \\ Lays Xavier de Castro², \\ Michelle Cruz ${ }^{2}$ \\ Juliana Santos de Souza Hannum ${ }^{2}$, \\ Talles Marcelo G. de A. Barbosa ${ }^{1}$
}

\begin{abstract}
Resumo: A síndrome de Down é causada pela presença de três cromossomos 21 em todas ou na maior parte das células de um indivíduo [1]. As pessoas com síndrome de Down, ou trissomia do cromossomo 21, têm 47 cromossomos em vez de 46, como a maior parte da população. A pessoa com síndrome de Down tem idade cronológica diferente de idade funcional, desta forma, não é esperada uma resposta idêntica à resposta das pessoas com desenvolvimento típico [9]. Esta deficiência advém de desajustes funcionais do sistema nervoso, causando dificuldade no aprendizado. Essas dificuldades podem ser manifestadas desde a alfabetização básica até a realização de atividades cotidianas. O software desenvolvido neste trabalho tem o intuito de auxiliar pessoas com síndrome de Down durante o processo de alfabetização. $\mathrm{O}$ auxílio é fornecido por meio de atividades, como, por exemplo, o pareamento de vogais. Além disso, durante a execução dessas atividades, um algoritmo para biofeedback, conhecido como Attention Meter, monitora a atenção demonstrada pelos os usuários. Ao final, é gerado um relatório do desempenho para cada usuário, com marcadores que destacam o comportamento durante a execução de cada atividade. Assim, ao longo do processo de alfabetização, é possível quantificar e qualificar as atividades propostas não apenas pela quantidade de acertos, mas, também, pelo engajamento pessoal de cada usuário do aplicativo.
\end{abstract}

Palavras-chave: Síndrome de Down, Attention Meter, Biofeedback.

\begin{abstract}
Down syndrome is caused by the presence of three 21 chromosomes in all or most of an individual's cells [1]. People with Down syndrome, or trisomy 21, have 47 chromosomes in their cells instead of 46, like most of the population. The person with Down syndrome has a different chronological age of functional age, so an identical response is not expected to respond to people with typical development [9]. This deficiency comes from functional maladjustments of the nervous system, causing difficulty in learning. These difficulties can range from basic literacy to daily activities. The software developed in this work is intended to help people with Down syndrome during the literacy process. Help is provided through activities, such as vowel pairing. In addition, during the execution of these activities, an algorithm for biofeedback (known as Attention Meter) monitors the attention shown by the users of the application. At the end, a performance report is generated for each user, with markers highlighting the personal involvement during the execution of each activity. Thus, throughout the literacy process, it is possible to quantify and qualify the activities proposed not only by the quantity of correct answers, but also by the personal engagement of each user of the application.
\end{abstract}

Keywords: Down Syndrome, Attention Meter, Biofeedback.

\section{Introdução}

\footnotetext{
${ }^{1}$ Escola de Ciências Exatas e da Computação (ECEC), Pontifícia Universidade Católica de Goiás (PUC-GO), Goiânia (GO) Brasil

marcus.girolneto@gmail.com, dr-ramos-slmb@hotmail.com, talles@pucgoias.edu.br

${ }^{2}$ Departamento de Psicologia, Pontifícia Universidade Católica de Goiás (PUC GO), Goiânia (GO).

julianahannumpsi@yahoo.com, layscastro@me.com, michelleoliveira.psi@gmail.com
}

http://dx.doi.org/10.5335/rbca.v9i2.6633

Revista Brasileira de Computação Aplicada (ISSN 2176-6649), Passo Fundo, v. 9, n. 2, p. 2-13, jul. 2017 
Um jogo afetivo é aquele no qual o jogador também interage indiretamente com o jogo, por meio de interfaces que possibilitam capturar e interpretar sentimentos, usualmente, por meio dos sinais eletrofisiológicos [3]. Desses sinais podem ser extraídas informações sobre o estado emocional do jogador, por exemplo, sustos, medo, ansiedade, etc. O termo jogo afetivo é derivado do conceito Computação Afetiva, termo cunhado por Rosalind Picard, no MIT, nos anos 90. Computação Afetiva considera as emoções e os comportamentos para o desenvolvimento de sistemas computacionais de propósito especifico [4]. Neste projeto é adotado o termo biofeedback para designar funcionalidades que possibilitam implementar Computação Afetiva em aplicativos para a plataforma Android/RemixOS.

Ao longo da última década, vários projetos foram iniciados com objetivo de desenvolver aplicativos para o treinamento de pessoas com desenvolvimento atípico, considerando diferentes requisitos, como, dificuldades motoras, déficits cognitivos e, até mesmo, comportamentais. Em destaque, o Participar [5] (Fig. 1(a) e Fig. 1(b)), o Livox [6] (Fig.1(e)), o vSked [7] (Fig. 1(d)) e o Mobile Communication Tools (MOCOTO) (Fig. 1(c)) [7], são projetos que vem sendo desenvolvidos para auxiliar na execução de atividades de reabilitação, utilizado o formato de jogos. Isto possibilita ampliar a interação e o engajamento dos usuários durante a execução das atividades propostas.

O projeto Participar propõe atividades para auxiliar na alfabetização básica, por exemplo, nomear os objetos em diferentes situações apresentadas aos usuários. O Livox propõe diversas atividades, desde alfabetização básica até atividades lúdicas, com o auxílio de músicas. Por exemplo, identificar palavras que se destacam em uma determinada música. A aplicação vSked vem sendo desenvolvida com base no conceito PECS (em inglês, Picture Exchange Communication System). O sistema PECS é uma metodologia para o auxílio de pessoas que não utilizam a comunicação verbal. Para isso, utiliza-se a troca de figuras, em desfavor da fala. Entretanto, atualmente, verifica-se que o PECS não é um inibidor da comunicação oral, mas, propicia estímulo adicional aqueles que ainda não consegue falar. O projeto MOCOTO também propõe a implementação do PECS em software, entretanto, apresenta outras funcionalidades, como, por exemplo, a possibilidade de adicionar novas imagens por meio de fotos capturadas pela câmera do dispositivo móvel. Isso possibilita aumentar o dicionário e customizar as imagens de acordo com o interesse do usuário e/ou de seu terapeuta.

Figura 1: Protótipos de Software extraídos dos projetos: (a) Expressar [5], (b) Expressar [5], (c) MOCOTO [7], (d) vSked [7], (e) LIVOX [6].
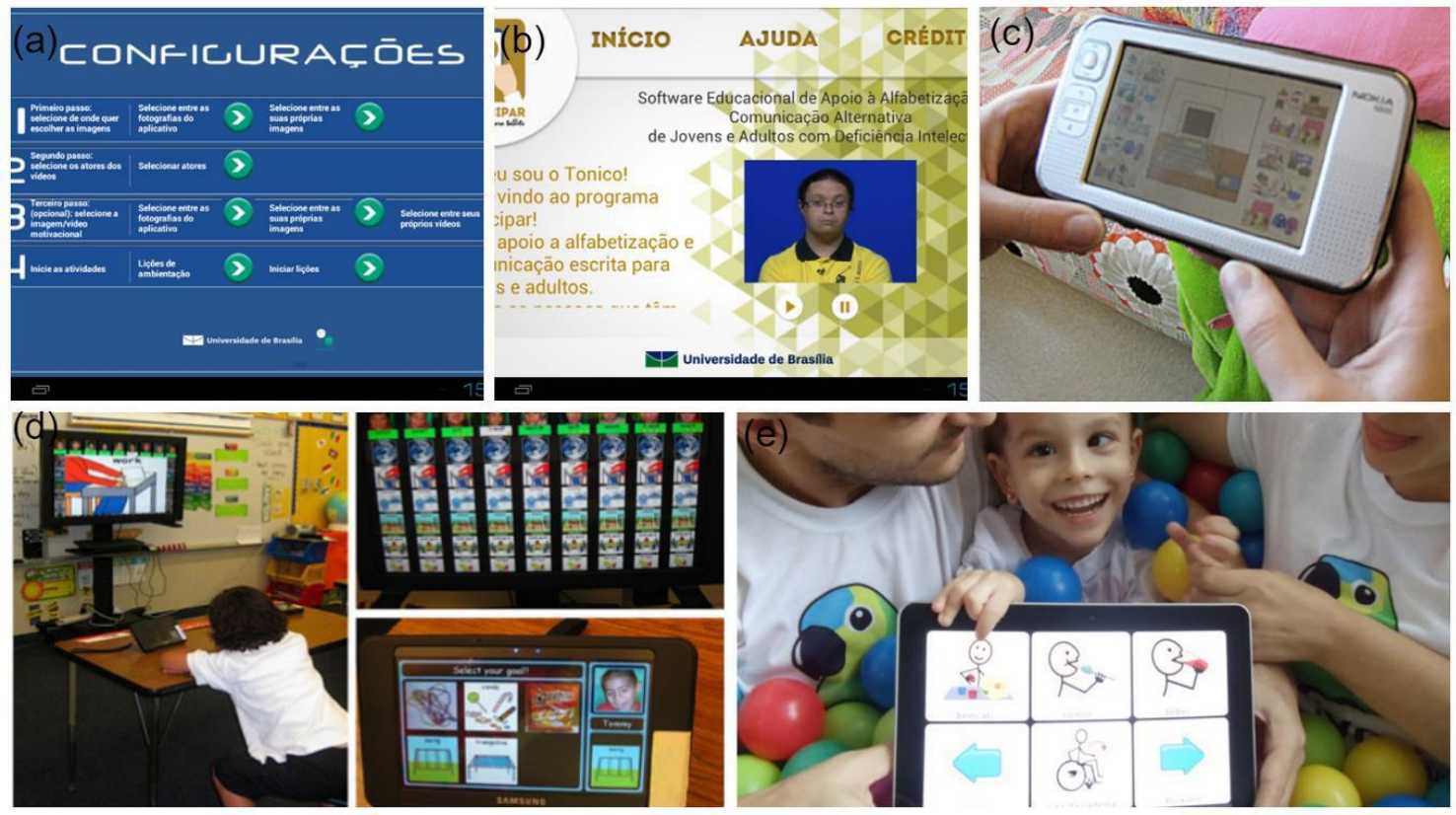

Os projetos supracitados disponibilizam recursos tecnológicos para assistência pessoas com atraso no desenvolvimento. Contudo, esses sistemas não dispõem de recursos para a verificação e/ou validação dos resultados com base no biofeedback. Entretanto, é sabido que variáveis fisiológicas e psicológicas podem influir no processo ensino-aprendizagem e, quando não são consideradas, dificultam o acompanhamento do usuário à distância, por meio da Internet. Além disso, a ausência de biomarcadores, na verificação dos resultados, impõem subjetividade ao processo, em razão da experiência prévia e individual de cada avaliador. Este trabalho tem como principal contribuição a inclusão do biofeedback como ferramenta que possibilita o

Revista Brasileira de Computação Aplicada (ISSN 2176-6649), Passo Fundo, v. 9, n. 2, p. 2-13, jul. 2017 
acompanhamento de um usuário de um sistema de software, à distância, quando submetido às atividades implementadas como funcionalidades da aplicação. Especificamente, neste trabalho, o biofeedback é implementado por meio de uma webcam para a verificação do nível de atenção do usuário durante a utilização do software. Ao final, todos os registros são armazenados na Internet, possibilitando que o profissionais assistentes possam verificar e avaliar todas as tarefas previamente propostas.

$\mathrm{Na}$ Pontifícia Universidade Católica de Goiás (PUC-GO), vem sendo desenvolvido um projeto de extensão e pesquisa que propõe auxiliar pessoas com síndrome de Down, em atividades que promovam o desenvolvimento pessoal e interpessoal, por intermédio de recursos computacionais. O projeto é denominado Alfadown e foi subdividido em dois níveis: o nível rudimentar e o nível avançado. O nível rudimentar atua com as pessoas que necessitam de atividades para alfabetização básica, por exemplo, conhecer e reconhecer o alfabeto. O nível avançado auxilia pessoas previamente alfabetizadas, com objetivo de aprimorar habilidades e desenvolver talentos, pela aplicação de atividades mais complexas, como, por exemplo, utilizar o semáforo para atravessar a rua. Diante disso, são desenvolvidos e utilizados aplicativos para as plataformas Windows e Android, desde software básico até ambientes de realidade aumentada, que possibilitam amplificar os estímulos utilizados no processo de ensino-aprendizagem. Diante disso, este artigo relata também os resultados acerca do desenvolvimento de um aplicativo para a plataforma Android, que disponibiliza funcionalidades de Computação Afetiva. O aplicativo foi construído para auxiliar na alfabetização de pessoas com síndrome de Down disponibilizando atividades para o letramento e para o estímulo sensorial. A execução das atividades deve ser monitorada por um algoritmo de biofeedback, que utiliza a câmera do dispositivo como sensor. Ao final, são gerados relatórios para análise do desempenho do aluno durante a atividade e, em seguida, submetidos aos profissionais que o acompanham.

Para enfatizar o que é proposto nas funcionalidades do software e aprimorar o aprendizado dos alunos, são utilizados reforços e repetições. As repetições foram utilizadas para que, desta forma, pudesse ser aplicada a técnica de aprendizado por repetição. Ou seja, aplicando a mesma atividade mais de uma vez é possível enfatizar o que é proposto e, assim, conseguir avanços no desenvolvimento pessoal. Os reforços são utilizados para melhorar o engajamento do aluno na atividade, em situações de erros e acertos. Em situações de erro, são utilizados estímulos que evitam a desistência e estimulem uma nova tentativa. Os estímulos são mensagens de incentivo emitidas pelo software e apresentadas por meio de voz, imagem e vídeos. Em situações de acerto, reforços positivos são exibidos. Estes, são elogios, palmas e saudações pelo resultado alcançado.

Além disso, o aplicativo fornece mecanismos que possibilitam a customização das atividades propostas. Uma aplicação personalizável auxilia na configuração do software conforme o perfil de cada usuário, de acordo com sua necessidade. Por exemplo, alguns alunos do projeto Alfadown não possuem coordenação motora suficiente para a execução de uma atividade que requer o arrastamento do dedo sobre a tela. Portanto, neste caso, a melhor alternativa é realizar a atividade por meio de cliques. Esta configuração pode ser realizada localmente, pela seleção dos parâmetros na tela de configuração do software, ou remotamente, por meio da plataforma Google Drive [8], substituindo os arquivos de configuração previamente configurados.

\section{Materiais e Métodos}

A aplicação desenvolvida neste trabalho fornece suporte a dispositivos que utilizam o sistema operacional Android. Este sistema operacional foi escolhido pela maior independência do hardware, maior número de dispositivos compatíveis, incluindo os compatíveis com o RemixOS [10]. Além disso, dispositivos que utilizam o sistema Android são geralmente mais acessíveis, no Brasil, em razão do menor custo, quando comparados aos concorrentes. Em especial, isto facilita o acesso dos alunos matriculados no projeto Alfadown à tecnologia mobile, possibilitando a execução de atividades, à distância.

Para o desenvolvimento do aplicativo foi utilizado o ambiente de desenvolvimento integrado Android Studio [9]. Esta ferramenta é fornecida pelo Google e possibilita o desenvolvimento de aplicações para dispositivos que possuem sistema operacional Android. O Android Studio possui algumas vantagens em relação a outras plataformas de desenvolvimento, como, por exemplo, a facilidade para o desenvolvimento de interfaces gráficas para os programas, de diferentes dispositivos.

Para a aplicação dos testes de software, foram utilizados diferentes dispositivos compatíveis com o sistema operacional Android: i) o Computer Stick/Intel [11] (Fig. 2a) com a versão 5.0 do sistema Android, ii) o tablet Acer Iconia A500 (Fig. 2b), Android 4.0 e iii) o PC/Intel com o sistema Remix OS (Fig. 2c), Android 6.0 [10]. O Remix OS é uma versão do sistema operacional Android para desktop e notebook. O dispositivo Compute Stick/Intel possibilita transformar qualquer monitor, incluindo televisores de uso doméstico, em um computador pessoal, para a execução do software desenvolvido neste trabalho.

Revista Brasileira de Computação Aplicada (ISSN 2176-6649), Passo Fundo, v. 9, n. 2, p. 2-13, jul. 2017 
Figura 2: Execução da aplicação (software) nas plataformas. (a) Compute Stick; (b) Tablet Acer Iconia A500; (c) Remix OS.
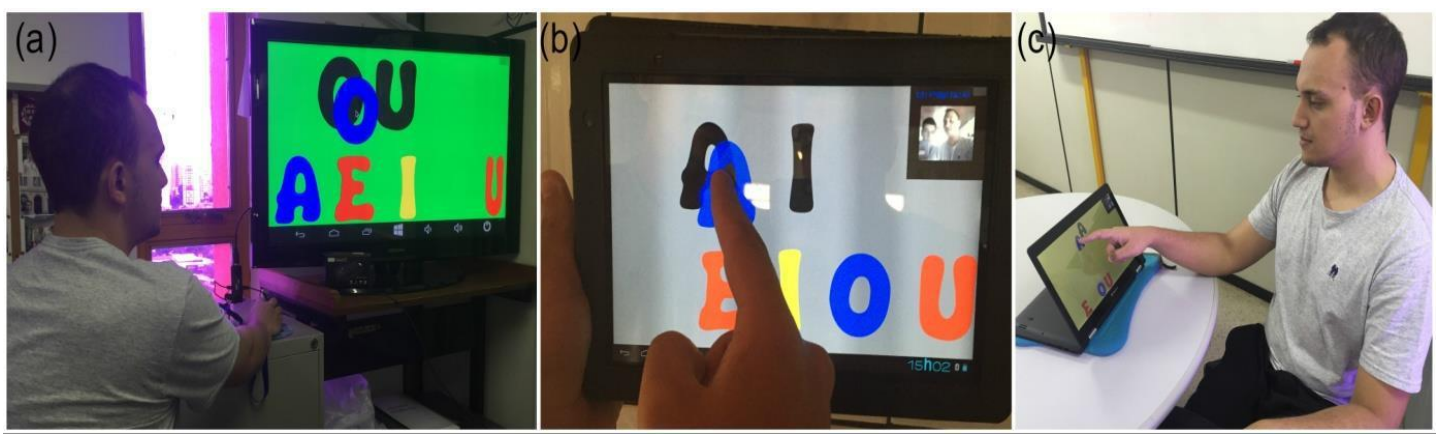

A Fig. 3 sintetiza o processo utilizado para o desenvolvimento do Lori's Help. Para a elicitação dos requisitos foram realizadas reuniões com professores e monitores do projeto Alfadown. Após a coleta dos requisitos, as funcionalidades propostas para o software foram implementadas, durante a atividade "Execução", mostrada na Fig. 3. Com a finalidade de revelar possíveis erros de lógica e codificação, testes de caixa branca foram realizados para cada funcionalidade do software. Ao final, os artefatos da documentação foram gerados. Em seguida, foram aplicados testes de caixa preta, durante a atividade "Análise de Resultados". Ao final, a geração dos manuais de uso do software e a criação de um site para disponibilização dos artefatos de programa foram executadas, atividade "Manual" (Fig. 3).

Figura 3: Diagrama de atividade do processo de desenvolvimento da aplicação.



Para a verificação de possíveis erros na aplicação foram realizados dois tipos de testes: testes de caixa branca e testes de caixa preta. Os testes de caixa branca foram realizados para a verificação dos artefatos de software. Portanto, por meio de assertivas, utilizando a ferramenta Android Studio, dados de entrada específicos são informados e, em seguida, é verificado se a saída de determinada função está em conformidade. Os testes de caixa preta foram executados para verificação de erros, no uso da ferramenta, como eventuais travamentos, vazamento de elementos gráficos da tela, entre outros.

Para a configuração remota dos parâmetros do software, foi utilizado um arquivo de configuração. Assim, os avaliadores podem modificar o funcionamento do aplicativo, à distância, pela Internet. Para isso, a plataforma 
Google Drive [8] foi utilizada. Com a finalidade de alterar os parâmetros do software remotamente, um arquivo de configuração, no formato JSON é disponibilizado e armazenado na plataforma Google Drive. O JSON (em inglês, JavaScript Object Notation) é basicamente um formato para troca de dados entre sistemas [12]. Este formato possui algumas vantagens, dentre elas: leitura mais simples, analisador (parsing) mais simples, menor tempo para a transmissão e processamento dos dados. A simplicidade refere-se à facilidade de compreensão da sintaxe do texto pelo uso dos metadados inseridos no mesmo arquivo.

O arquivo de configuração possui os parâmetros para o funcionamento adequado da aplicação, tais como, a atividade que deve ser realizada pelo aluno, o número de repetições de cada atividade e etc. O projeto Alfadown atende diversos alunos que possuem aspectos específicos e únicos. Desta forma, o aplicativo deve ser customizado para cada perfil de aluno. Portanto, a conta do Google Drive informada para a aplicação precisa separar as características de cada aluno em arquivos de configurações distintos. Com isso procura-se organizar os perfis de cada aluno, por meio de seu arquivo individual de configuração, evitando assim uma inconsistência dos dados.

O monitoramento da atenção por meio da câmera, embutida no dispositivo mobile, utiliza o algoritmo de biofeedback conhecido como Attention Meter [13]. O algoritmo monitora a variação de micro expressões faciais. Com isso, ao observar alterações na movimentação da face do usuário, o nível de atenção é mensurado $\mathrm{O}$ monitoramento da atenção pode ser executado de forma online, durante a execução da atividade, ou de forma off-line. Neste caso, apenas o vídeo é gravado durante a execução da atividade. Em seguida, ele é enviado ao repositório, no Google Drive, para o processamento à posteriori. Cumpre destacar que a gravação do vídeo pode ser executada concomitantemente com a gravação da tela, manipulada pelo usuário. Isto possibilita a análise comportamental do usuário, pela Internet. Ainda, a obtenção de variáveis fisiológicas, como, por exemplo, a frequência cardíaca, após o processamento do vídeo [14]. Neste projeto foi utilizada uma implementação do Attention Meter desenvolvida por Douglas et al [15].

\subsection{Descrição Estrutural}

O diagrama de classes apresentado na Fig. 4 ilustra a estrutura do software desenvolvido neste trabalho, apresentando os principais componentes e a inter-relação entre eles. Também, mostra a associação existente entre os blocos "Aplicação", "Framework Biofeedback" e "DriveAPI". O bloco de "Aplicação" contém as classes responsáveis pelas atividades principais e o menu de configuração da aplicação. O "Framework Biofeedback" possui os recursos do algoritmo de Attention Meter, como, por exemplo, a detecção da face do usuário. O "DriveAPI" compreende as funcionalidades implementadas pela API (em inglês, Application Programming Interface) do Google Drive, como, por exemplo, o envio e leitura de arquivos online.

As classes "AtividadeClicar" e "AtividadeArrastar", presentes no bloco de "Aplicação", são responsáveis pela implementação dos eventos clicar e arrastar respectivamente. Ao optar-se por executar as atividades pela configuração de arrastar, as classes "MyTouchListener" e "MyDragListener" são responsáveis pelo monitoramento da tela do aplicativo. O "MyTouchListener" monitora os eventuais cliques nas letras de cada tela. Cada uma possui um identificador, representado por um número inteiro. Desta forma, ao clicar-se na letra um evento, contendo o identificador desta, é gerado. Concomitantemente, a classe "MyTouchListener" monitora a tela da atividade para verificar o ponto onde a letra selecionada será solta. Se o ponto e o identificador da letra e da sombra forem equivalentes uma mensagem de acerto é então apresentada.

O bloco "Aplicação" ainda contem as classe "MainActivity" e "ConfigScreen". A "MainActivity" é responsável pelas funcionalidades do envio e leitura do arquivo de configuração para a plataforma Google Drive. Esta classe também implementa a tela inicial da aplicação, que apresenta botões para acessar outras funcionalidades da aplicação, como, por exemplo, modo de demonstração e menu de configuração. Este menu de configuração é implementado na classe "ConfigScreen". Este menu apresenta todos os parâmetros responsáveis pela configuração do software, disponibilizando ao usuário a possibilidade de alteração dos mesmos.

O algoritmo que executa o monitoramento da atenção do usuário (Atttention meter) é implementado no bloco "Framework Biofeedback". Os recursos para armazenamento dos vídeos dos usuários e configuração remota, disponibilizados pela plataforma Google Drive, são oferecidos por meio das classes contidas no bloco "DriveAPI". Por exemplo, a classe "GoogleApiClient" disponibiliza acesso aos arquivos compartilhados na plataforma Google Drive. Para isso, são executadas operações de autenticação, leitura, escrita e o envio de arquivos.

\subsection{Protótipo}

Após a implementação das funcionalidades propostas e verificações de possíveis erros de programação um protótipo foi desenvolvido. Este, implementa 4 atividades elaboradas para o auxílio no processo de alfabetização e estímulos sensoriais dos alunos do projeto Alfadown. Além disso, foi implementado um menu 
que possibilita configurar de forma especifica cada uma das atividades do software. A Fig. 5 ilustra um fragmento do menu de configuração. A Fig. 6 ilustra uma das atividades desenvolvidas para o auxílio na alfabetização.

Figura 4: Diagrama de classes do software.

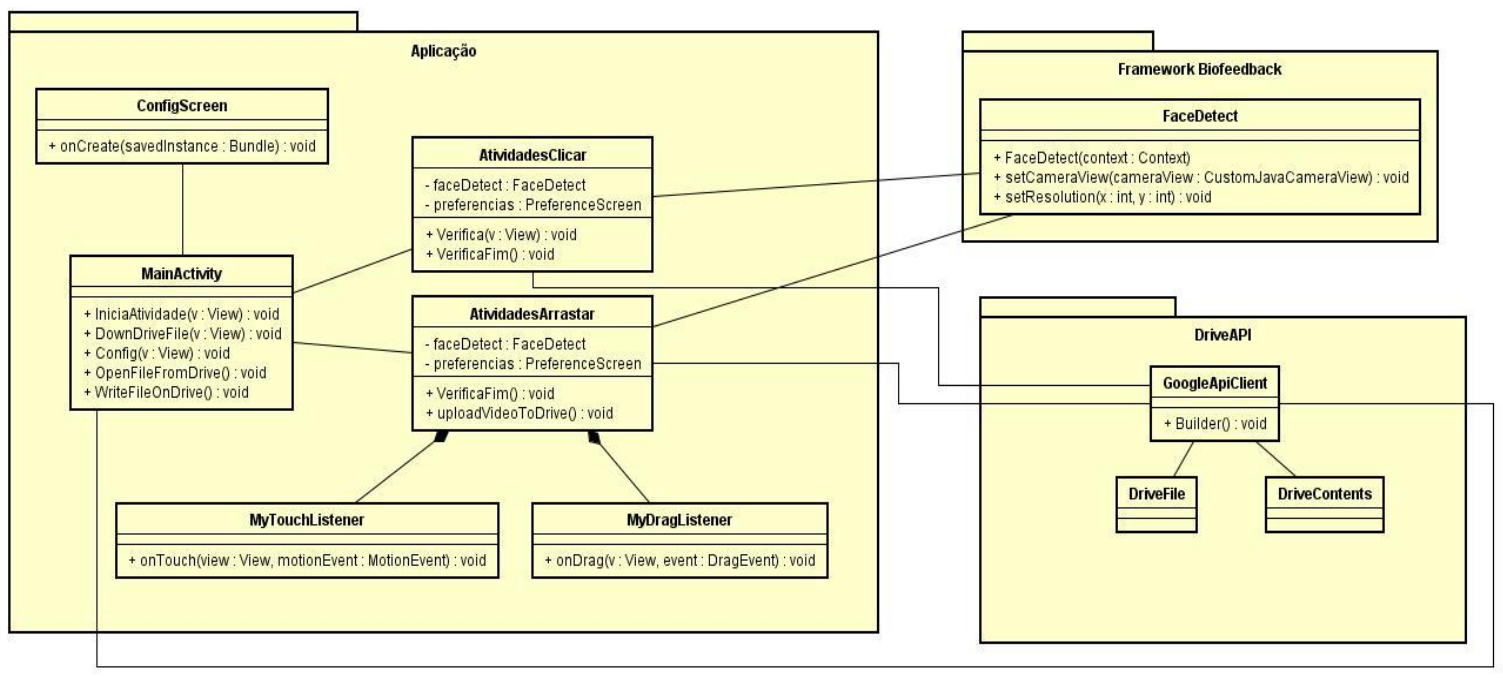

Para realizar as alterações remotas nos parâmetros do software, foi utilizado o formato JSON. Um arquivo JSON é composto por metadados e dados (Fig. 7). O metadado é o campo relativo à qual informação se deseja alterar, por exemplo, qual câmera será utilizada pelo Attention Meter. Já o dado é a informação desejada, ou seja, como no exemplo supracitado, a seleção de qual das câmeras deve ser utilizada para o monitoramento (frontal ou traseira). Para que os parâmetros da aplicação possam ser alterados, é realizada uma análise léxica sobre os dados presentes no arquivo JSON. Caso algum campo não esteja em conformidade com padrão estabelecido, uma mensagem é exibida informando a possível inconformidade.

Uma das funcionalidades implementadas no protótipo do aplicativo é a gravação de vídeos da face dos usuários durante a realização de uma atividade. Desta forma, uma análise a posteriori pode ser realizada sobre as gravações. Durante uma sessão, o usuário pode variar suas micro expressões faciais, por exemplo, o movimento dos olhos, boca, testa, etc. Por meio do vídeo gravado o algoritmo de biofeedback pode inferir sobre o nível de atenção e então mensura-lo.

Figura 5: Fragmento da tela de configuração da aplicação.

\section{ATIVIDADES ALFABETIZAÇÃO}

\section{Numero de Repetições}

Escolha o numero de vezes que será executada cada atividade

\section{Numero Repetições Vogal}

Numero de repetições de uma mesma vogal para atividade de vogais

\section{ATIVIDADE SONS E IMAGENS}

\section{Pontuação Máxima}

Numero máximo de vitórias

\section{APLICAÇÃO DO ATTENTION METER}

Camera

Escolha qual camera sera utilizada para a captura 
Figura 6: Atividade de pareamento de palavras com o algoritmo de biofeedback executando no plano de fundo.



Figura 7: Estrutura de um arquivo JSON

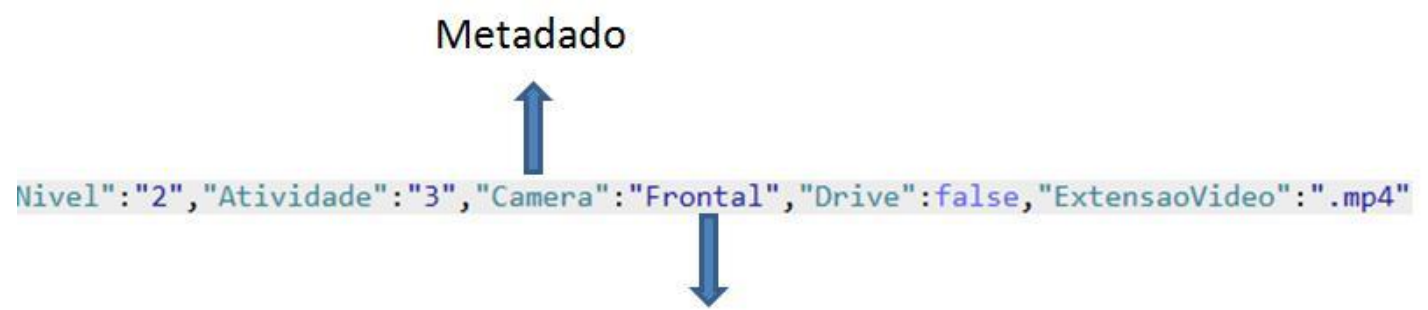

Dado

\section{Testes com Dados do Projeto Alfadown}

A criação do protótipo possibilitou a aplicação de testes de usabilidade nos alunos do projeto Alfadown. Para os testes foram utilizados os computadores disponíveis no ambiente do projeto. Estes são fabricados pela Samsung no modelo Essentials All in One E3 TV [16] e são iniciados com o sistema Remix OS, por meio de um pen drive. Desta forma, os alunos realizaram os testes em um local onde já estão habituados, com a presença de seus respectivos monitores. Para evitar eventos que pudessem provocar desatenção, como ruídos, movimentação de pessoas, apenas um aluno por vez foi submetido à sessão de testes. Cumpre destacar que a execução dos testes com os alunos do projeto Alfadown foi aprovada pelo comitê de ética em pesquisa, pelo Certificado de Apresentação para Apreciação Ética (CAAE): 32702 114.2.0000.0037.

Para organizar e possibilitar a aplicação dos testes nos alunos, um roteiro de testes foi elaborado. O roteiro de testes consiste em um conjunto de atividades elaboradas para possibilitar a aplicação do software nos alunos. Inicialmente, após discussões com a equipe envolvida no projeto, como professores e monitores, foram definidas as perguntas que deveriam ser apresentadas no questionário de avaliação de software. A Fig. 8 ilustra o questionário de avaliação de software.

Após a elaboração do questionário (Fig. 8), os testes de usabilidade da aplicação foram realizados nos alunos do projeto Alfadown. Cada atividade possui um objetivo específico. $\mathrm{Na}$ atividade de pareamento vocálico o objetivo é avaliar o reconhecimento dos símbolos (caractere). O pareamento de encontros vocálicos procura avaliar o reconhecimento dos fonemas. Na atividade de pareamento de palavras o objetivo é avaliar a capacidade dos alunos de juntar encontros e formar palavras dissílabas. Com a atividade de estimulo sensorial, o objetivo é 
verificar a capacidade dos alunos de relacionar imagens com os respectivos sons que a representam. A Fig. 9 mostra um aluno do projeto Alfadown utilizando o software desenvolvido.

Para iniciar os testes com os alunos, foram definidas as configurações do software. Para todos os testes foram utilizadas cinco repetições para cada atividade. Esta quantidade de repetições foi estabelecida com o objetivo de avaliar o processo, minimizando o efeito de resultados inconsistentes (outliers) e sem provocar estresse mental nos alunos. Em todas as atividades, o recurso arrastar foi selecionado, pois, assim, foi possível avaliar eventuais dificuldades motoras apresentadas pelos alunos. Durante os testes as atividades executadas pelos alunos concomitantes com as expressões faciais foram gravadas no formato de vídeo, para analise a posteriori.

Ao final de cada sessão de testes, o monitor responsável pelo aluno preencheu um questionário de avaliação. A Fig. 8 ilustra o modelo de questionário preenchido no final de cada teste. O processo de aplicação dos testes é descrito na Figura 10.

Figura 8: Questionário de avaliação de software: (a) Atividade 1: Pareamento Vocálico. Atividade 2: Pareamento Encontros Vocálicos. Atividade 3: Pareamento Palavras. (b) Atividade 1: Relacionar o áudio com a Imagem.

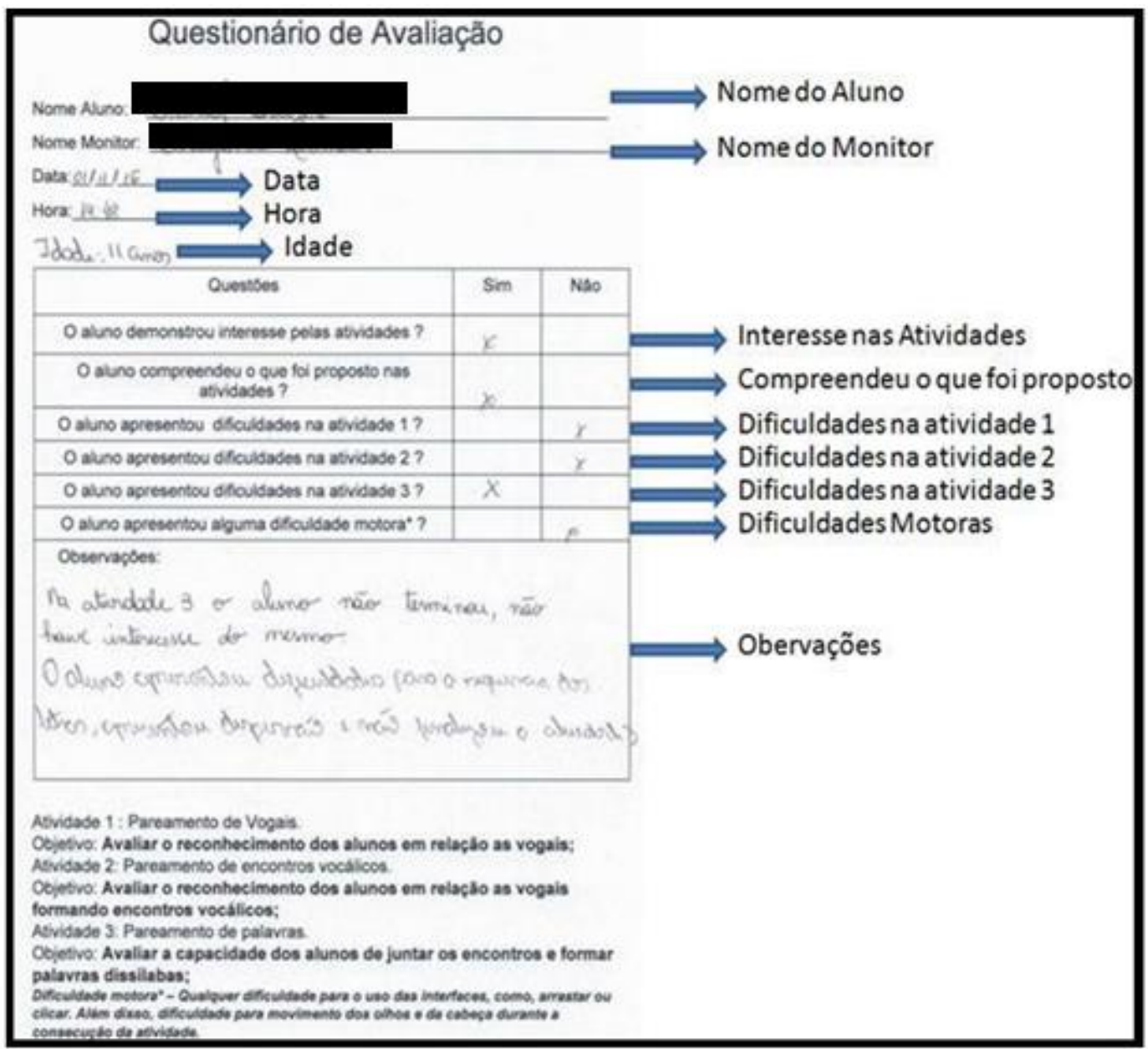


Figura 9: Aluno realizando uma das atividades do software.

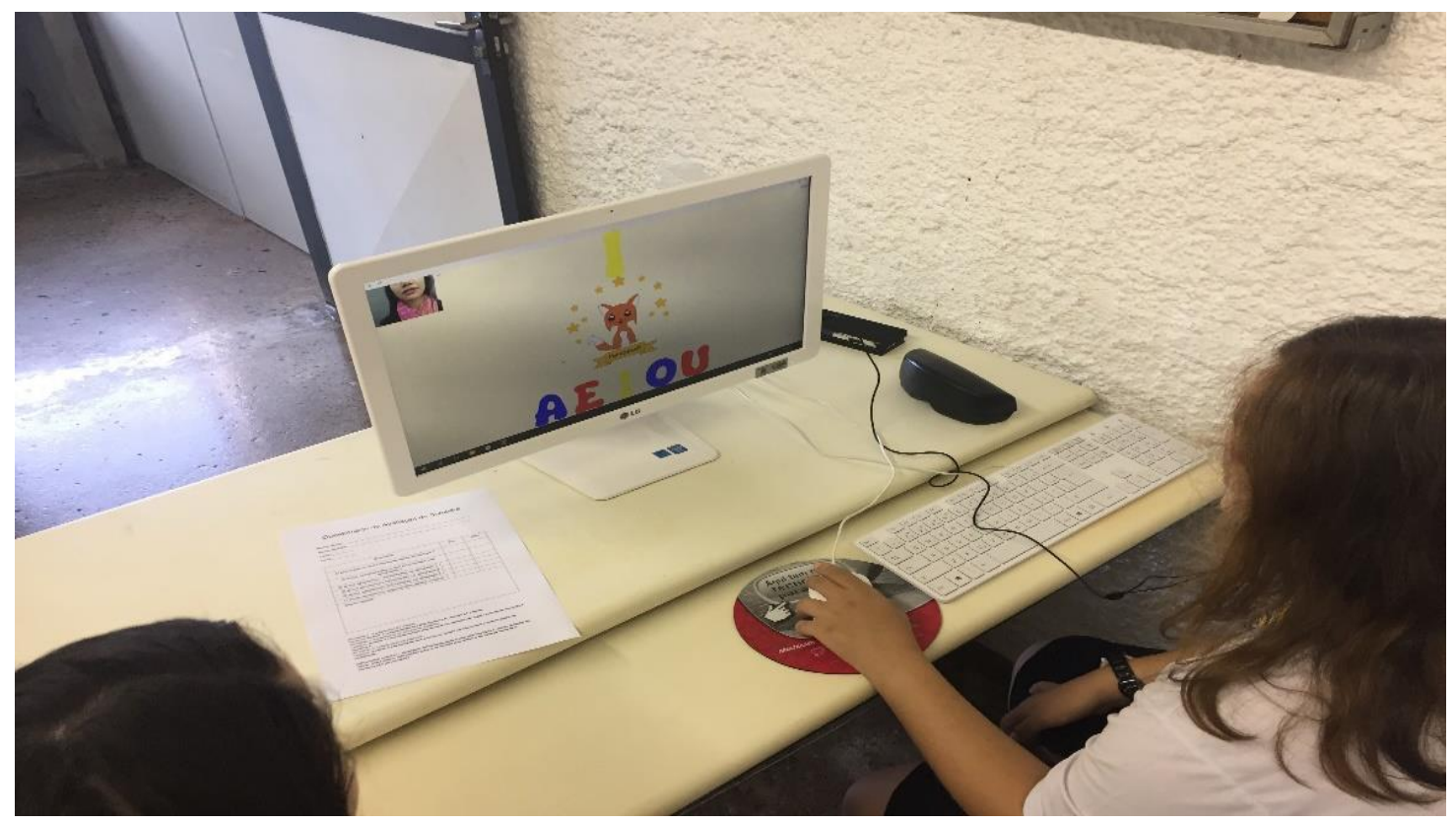

Figura 10: Diagrama de atividade que descreve o processo de testes

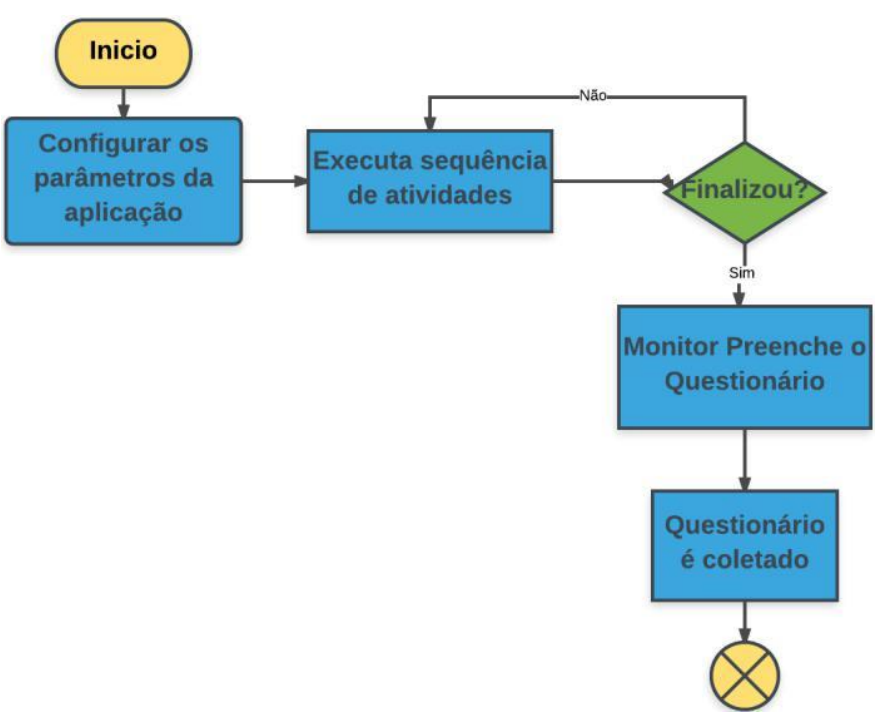

\section{Resultados}

Com o término dos testes do aplicativo nos alunos do projeto Alfadown, os relatórios preenchidos pelos monitores foram recolhidos. Em seguida, iniciou-se o processo de análise estatística dos dados. Após o cálculo das variáveis estatísticas e valores de probabilidade, foi utilizada a distribuição binomial para inferências sobre os dados obtidos dos questionários. A distribuição binomial está associada a situações que envolvem apenas dois possíveis resultados: sucesso ou fracasso [17]. A Figura 8 ilustra as duas possíveis respostas para as questões utilizadas nos testes de usabilidade. Portanto, verifica-se a existência de um número fixo de ensaios, cada ensaio possui duas possibilidades: sucesso ou fracasso, a probabilidade de sucesso é a mesma para cada ensaio e os ensaios são independentes, ou seja, o resultado de um não interfere nos demais.

A Figura 11 e a Figura 12 ilustram as probabilidades calculadas sobre os dados obtidos por meio dos testes nos alunos. Esses cálculos foram realizados com base nos dados relatados pelos monitores sobre o desempenho dos alunos nas atividades do software. Conforme calculado sobre os dados, $93.33 \%$ dos alunos demonstraram compreender o que foi proposto nas atividades (Figura 11(a)). Enquanto 86.66\% demonstraram interesse na realização das atividades propostas no aplicativo (Figura 11(c)). Portanto, nem todos os alunos que 
compreenderam o que foi proposto se sentiram confortáveis, ou se interessaram, em realizar as atividades propostas. Alguns alunos se sentiram cansados ao repetir a mesma atividade por 5 vezes, número proposto de repetição para os testes, deixando-os desconfortáveis durante realização da atividade.

Segundo os dados obtidos, $33.33 \%$ dos alunos apresentaram alguma dificuldade motora (Figura 11(b)). Dificuldade motora foi caracterizada como qualquer dificuldade para utilizar os dispositivos como, por exemplo, o mouse ou, ainda, dificuldades em parear as letras com suas respectivas sombras. Desta forma, a hipótese que o aluno pode apresentar dificuldades em parear as letras arrastando-as pode ser percebida.

Durante a realização dos testes, iniciando pela atividade para o pareamento vocálico, foi percebido um crescimento com tendência linear acerca das dificuldades apresentadas pelos alunos. Ou seja, os alunos apresentaram um menor percentual de dificuldade na realização da atividade de pareamento vocálico e um maior percentual de dificuldade na execução da atividade de pareamento de palavras. Isto corrobora com a necessidade de crescimento incremental do nível de dificuldade oferecido pelo aplicativo para as atividades 1,2 e 3. A atividade para o estímulo sensorial proposta na aplicação, cujo objetivo é relacionar sons às respectivas imagens, possui propósito diferente das 3 primeiras atividades. Enquanto elas procuram auxiliar na alfabetização, a atividade 4 possibilita o estímulo sensorial. Dentre os testes realizados, $33.33 \%$ dos alunos apresentaram alguma dificuldade para a realização da atividade 4 (Fig. 11(d)). Essas dificuldades podem ser: dificuldades para identificar os sons e/ou dificuldades para associar o som à figura.

Figura 11: Probabilidades calculadas dos dados obtidos por meio dos testes. (a) Alunos compreenderam o que foi proposto. (b) Dificuldades na atividade 4. (c) Alunos demonstraram interesse na atividade. (d) Alunos que apresentaram dificuldade motora.

(a)

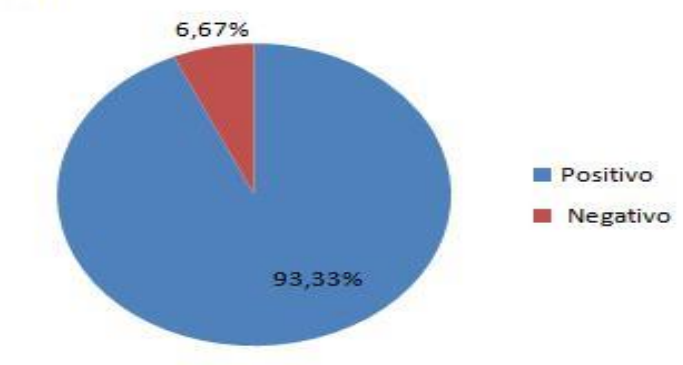

(c)



(b)

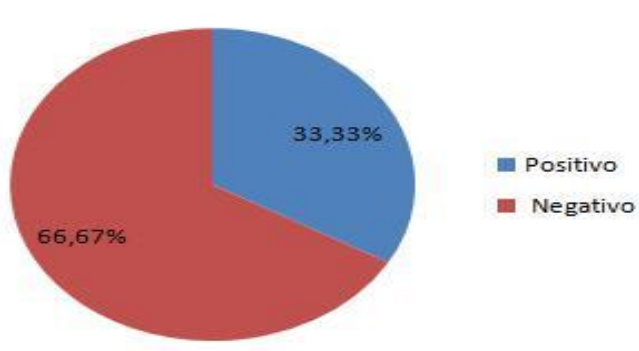

(d)

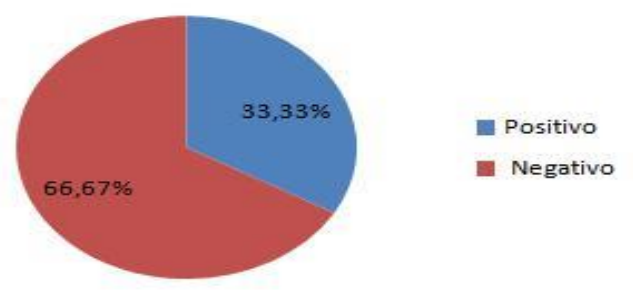


Figura 12: Percentual de dificuldade encontrada nas atividades de alfabetização. O nível de dificuldade cresce com tendência linear.

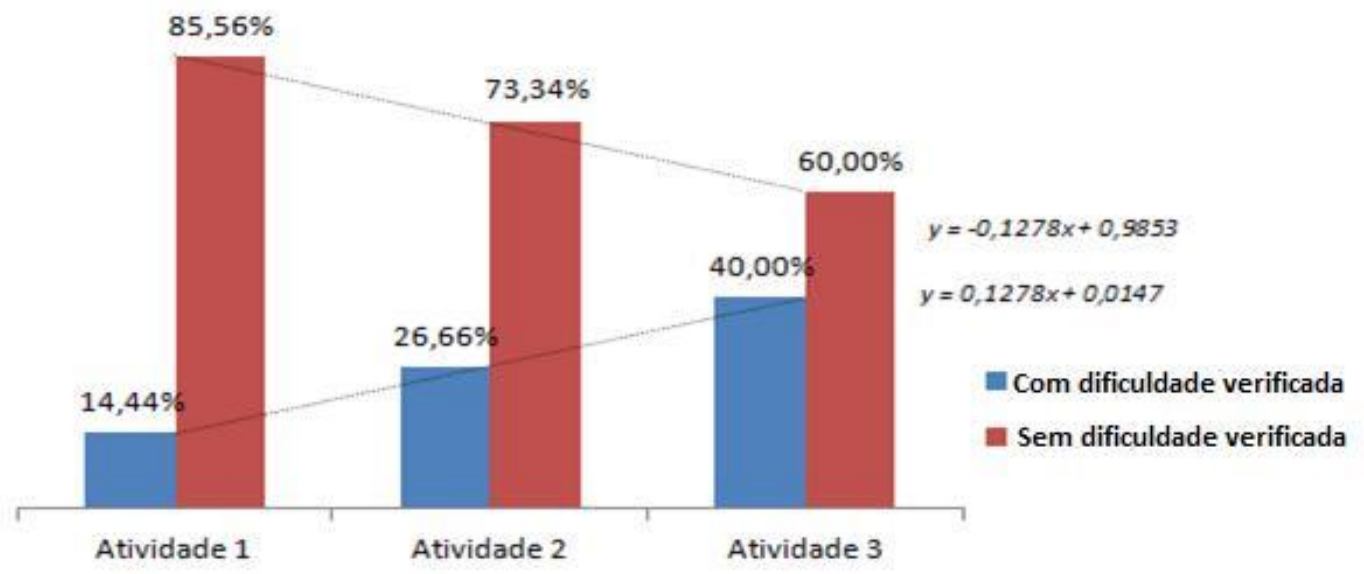

\section{Discussões}

Durante o desenvolvimento do protótipo as mensagens utilizadas pelos reforçadores sonoros foram definidas com a equipe do projeto. Essas mensagens foram estipuladas por meio de reuniões com os monitores, psicólogos e pedagogos do projeto Alfadown.

As atividades fornecidas para o auxílio na alfabetização utilizam as letras do alfabeto. Desta forma, o desenvolvimento de fontes gráficas para tornar a letra compreensível, com traços e cores atrativas, foi necessário. Estas, devem ser dispostas de forma clara nas telas das atividades. Desta forma, os usuários não encontraram dificuldades para o entendimento. Juntamente com as letras, as imagens e sons selecionados para o aplicativo devem ser claros e nítidos, deste modo, o usuário foi capaz de compreender a imagem e os sons apresentados nas atividades.

Durante a implementação do software alguns desafios foram percebidos. Por exemplo, o monitoramento de cada atividade por meio do algoritmo de biofeedback necessita de um estudo mais preciso sobre micro expressões faciais. Este estudo é necessário para analisar vídeos e imagens de faces com diferentes expressões. Com essa análise, pode-se treinar o algoritmo de Attention Meter para torna-lo mais preciso em suas aferições sobre o nível de atenção dos usuários.

\section{Conclusões}

Aplicações que auxiliam pessoas com desenvolvimento atípico fornecem suporte para a execução de atividades que contribuem para o aprendizado. Contudo, essas aplicações não disponibilizam recursos de biofeedback. Desta forma, o desempenho é avaliado apenas pela quantidade de acertos anotados pelo software, durante a execução das atividades.

O aplicativo desenvolvido neste projeto disponibiliza recursos de monitoramento à distância, para avaliação off-line, além de recursos para monitoramento automático e online da atenção e/ou da dispersão dos usuários. Esses recursos possibilitam o biofeedback para a avaliação e/ou customização das atividades propostas aos usuários. Com isso, após o término de uma atividade, é gerado um relatório informando ao monitor sobre o desempenho do aluno na execução da atividade proposta. O relatório gerado pode também, ser encaminhado para um profissional da área da saúde, por exemplo, psicólogo. Este psicólogo pode então analisar o desempenho do aluno sem necessidade de uma avaliação presencial.

A criação de uma tela de configuração, que torna a aplicação parametrizável conforme a necessidade do usuário auxilia no aprendizado de cada aluno. Partindo do pressuposto que cada usuário possui necessidades diferentes, a configuração individual customizada para cada individuo é indispensável para o uso clínico da ferramenta. A possibilidade de alterar parâmetros remotamente, por meio de um arquivo de configuração armazenado na plataforma Google Drive, facilita a customização das atividades, à distância, pela Internet. Com 
isso, existe a possibilidade de estender as atividades realizadas no ambiente de ensino, no caso projeto Alfadown, para a casa dos alunos.

O aplicativo propõe atividades para o auxílio na alfabetização dos usuários com a síndrome de Down. Juntamente com as atividades, a aplicação disponibiliza recursos multimídia para o estimulo na realização das mesmas. Com os recursos multimídia os alunos se sentem estimulados a realizar as atividades, visto que, os reforços visam incentivar na realização e término da atividade. Os reforços são apresentados como forma de parabenizar, quando o aluno acerta determinada atividade, e como forma de incentivar, quando o usuário comete algum tipo de erro. Esses recursos são apresentados também para informar ao aluno o roteiro que ele deve seguir para a execução da atividade.

Em trabalhos futuros, devem ser implementadas novas atividades para letramento. Por exemplo, atividades que utilizam recursos musicais para ensino de palavras por meio de músicas. Em uma determinada música, o aluno poderia ser desafiado a repetir uma palavra específica destacada. O uso de comandos de voz pode ser adicionado à ferramenta desenvolvida. Com isso, é possível avaliar a pronuncia correta das letras do alfabeto.

Além das funcionalidades propostas, o recurso de gravação da tela simultaneamente a gravação do vídeo com a face do usuário pode ser desenvolvido. Esse recurso é interessante pois, ao gravar a tela juntamente com a face do usuário pode-se obter confirmações sobre o que o algoritmo Attention Meter retornou como resultados. Desta forma, além do algoritmo de biofeedback, um profissional da saúde pode analisar os vídeos e obter conclusões.

\section{Agradecimentos}

Este trabalho contou com a colaboração das pessoas envolvidas com o projeto Alfadown. Em especial, as professoras Juliana Hannun e Pollyanna Rosa Ribeiro. As estudantes do curso de psicologia, da PUC-GO, Lays Xavier, Suellen Nunes, Cristiane de Paula, Lorena Lourenço e Michelle Cruz, cuja voz foi utilizada para as mensagens de reforço utilizadas no software. À Jessica Santillo, estudante de Engenharia de Controle e Automação, da PUC-GO, responsável pelo desenvolvimento dos elementos gráficos utilizados no aplicativo. À Rafaela Araujo, estudante de Engenharia de Computação, da PUC-GO, pelo desenvolvimento do framework de biofeedback utilizado no software.

A fundação de amparo à pesquisa do estado de Goiás (FAPEG) pelos recursos financeiros disponibilizados.

O aplicativo Lori's Help está disponível gratuitamente para download em: https://sourceforge.net/projects/lori-helps/

\section{Referências}

[1] O que é ?, Síndrome de Down. Disponível em: <http://www.movimentodown.org.br/sindrome-de- down/oque- e/>. Acesso 4 de outubro de 2016.

[2] BISSOTO. M. L. "Desenvolvimento Cognitivo e o Processo de Aprendizagem do Portador de Síndrome de Down: Revelando Concepções e Perspectivas Educacionais". Ciências e Cognição, 2009.

[3] GILLEADE. K. M.; DIX. A., ALLANSON. J. Affective Videogames and Modes of Affective Gaming: Assist Me, Challenge Me, Emote Me. 2009

[4] PICARD, R. W., and Roalind Picard. Affective computing. Vol. 252. Cambridge: MIT press, 1997.

[5] Projeto Participar, Expressar. Disponível em: <http://www.projetoparticipar.unb.br/expressar >. Acesso em 20 de agosto de 2016.

[6]. Livox, Livox. Disponível em: <http://www.livox.com.br/>. Acesso em 19 de agosto de 2016.

[7] HAYED. G. R.; HIRANO. S.; MARCU G.; MONIBI. M.; NGUYEN. D. H.; YEGANYAN. M. Interactive visual supports for children with autism. Pers Ubiquit Comput. 2010. 
[8] Google Drive, Google Drive. Disponível em: <https://www.google.com/intl/pt-BR/drive/>. Acesso em 03 de novembro de 2016.

[9] Android Studio, Android Studio. Disponível em: <https://developer.android.com/studio/index.html>. Acesso 15 de agosto de 2016.

[10] JIDE, Remix OS. Disponível em: <https://developer.android.com/studio/index.html>. Acesso 16 de agosto de 2016.

[11] Intel, Apresentação do Intel Compute Stick. Disponível em: <https://developer.android.com/studio/index.html>. Acesso 17 de agosto de 2016.

[12] Introdução ao JSON, JSON. Disponível em:<http://www.json.org/json-pt.html>. Acesso em 03 de novembro de 2016 .

[13] LEE, C. J., "Externalizing and Interpreting Autonomic Arousal in People Diagnosed with Autism", Program of Media Arts and Sciences, School of Architetural and Planning in partial fulfillment of the requirements for the degree of Doctor of Philosophi, Massachusetts Institute of Technology, September 2011.

[14] SOUZA, P. H. de B.; FERREIRA, J. O.; ROCHA, A. F.; BARBOSA, T. M. "A Noncontact Technique to Measure HRV", International Journal of Applied Information Systems (IJAIS) - ISSN : 2249-0868 Foundation of Computer Science FCS, New York, USA Volume 11 - No.1, Junho 2016.

[15] Douglas F. de M. SANTOS, E. “ELViS: Enhanced for Limited Vision System.”, International Journal of Applied Information Systems (IJAIS) - ISSN : 2249-0868 Foundation of Computer Science FCS, New York, USA Volume 9 - No.8, Outubro 2015.

[16] Samsung All in One E3 TV, Samsung. Disponível em: <http://www.samsung.com/br/consumer/it/all-inone/all-in-one/DP500A2L-KW3BR>. Acesso em 14 de dezembro de 2016.

[17] REIS, E.; MELO, P.; ANDRADE, R.; \& CALAPEZ, T. (1996). Estatística aplicada. Edições Sílabo. 